\title{
OPEN Recyclable NiO/sepiolite as adsorbent to remove organic dye and its regeneration
}

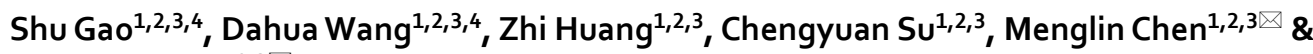 \\ Xiangfeng $\operatorname{Lin}^{1,2,3 凶}$
}

In this study, the impregnation synthesis of $\mathrm{NiO} /$ sepiolite and its application for dye removal during wastewater treatment is introduced. The $\mathrm{NiO} /$ sepiolite materials act as an adsorbent/catalyst. It comprises a unique combination of adsorption and high-temperature gas flow regeneration (the $\mathrm{NiO} /$ sepiolite acts as a catalyst at this stage, using regeneration rate as evaluation index of catalytic activity of $\mathrm{NiO} /$ sepiolite) in a single unit, in which the $\mathrm{NiO} /$ sepiolite was regenerated and reused for the next round adsorption of dye. An aqueous solution of methylene blue was used to evaluate the adsorption and regeneration performance of the adsorbent/catalyst. The regeneration rate reached $74 \%$ when the reaction time and temperature were $7 \mathrm{~min}$ and $350^{\circ} \mathrm{C}$, respectively. The effects of the regeneration temperature and volume fraction of $\mathrm{O}_{2}$ on the regeneration rate were investigated. And the regeneration reaction kinetics was provided. The combination of adsorptive and catalytic properties in the $\mathrm{NiO} /$ sepiolite composites received interesting results for removing refractory biodegradable organic pollutants. This work provides new insights for the removal of dye from wastewater using $\mathrm{Ni}$ catalysts supported on natural low-cost clay.

Synthetic dyes are a type of hazardous and toxic pollutant, and most of them are derived from the printing and dye industries. If not treated appropriately, dyes will cause damage to the environment and human beings. Hence, the removal of dye from waste effluents is environmentally important. Various methods, such as catalytic wet oxidation, coagulation, ultrafiltration, ozonation, sedimentation, reverse osmosis, flotation, precipitation, photodegradation, adsorption, biological processes, and others have been successfully applied for dye removal. Among these methods, improvements in the degradation efficiency, as well as reductions in the cost of organic substance removal ${ }^{1-4}$, are concerns.

The removal of pollutants from water by adsorption is one of the most promising techniques due to its operational convenience and low cost when applied to current water treatment processes ${ }^{1,5}$. Adsorption using activated carbons is highly attractive for removing toxic and refractory biodegradable organic contaminants ${ }^{6}$. However, this approach also has some shortcomings. For instance, it causes environmental problems when the activated carbons are exhausted and disposed of afterward in landfills or by incineration ${ }^{7}$. Therefore, it is important to regenerate the adsorbents and reuse them. Much attention has been paid to alternative regeneration techniques in recent years. These techniques include microbial regeneration ${ }^{8}$, wet oxidation processes ${ }^{9}$, chemical regeneration ${ }^{10-12}$, solvent regeneration ${ }^{13}$, microwave-assisted regeneration ${ }^{14}$, electrochemical regeneration ${ }^{6,15,16}$, solar regeneration ${ }^{17}$, and thermal regeneration ${ }^{18}$. Clearly, the above reports have strongly demonstrated general and very effective strategies to improve the regenerative performance. Among these regeneration techniques, thermal regeneration is effective for the reuse of adsorbents. In this study, it is shown that high-temperature gas flow regeneration processes are a promising option, since they are fast processes that are performed in situ within the adsorption column under ambient conditions and at lower temperatures. Our previous report demonstrated that high-temperature gas flow regeneration was an effective process ${ }^{19}$. This technique includes adsorption and high-temperature gas flow regeneration that takes place within a single unit. High-temperature gas flow regeneration demonstrates several potential advantages compared to thermal regeneration. (1) Shorter regeneration

\footnotetext{
${ }^{1}$ Key Laboratory of Ecology of Rare and Endangered Species and Environmental Protection, Guangxi Normal University, Ministry of Education, Guilin 541004, People's Republic of China. ${ }^{2}$ School of Environment and Resource, Guangxi Normal University, Guilin 541004, People's Republic of China. ${ }^{3}$ University Key Laboratory of Karst Ecology and Environmental Change of Guangxi Province, Guangxi Normal University, Guilin 541004, People's Republic of China. ${ }^{4}$ These authors contributed equally: Shu Gao and Dahua Wang. ${ }^{\boxplus}$ email: mlchen99@163.com; 310976435@ qq.com
} 
time. The regeneration rate can reach $75 \%$ after $7 \mathrm{~min}$ of reaction time under a high-temperature gas flow, while thermal regeneration may require much more time ${ }^{20}$, and (2) lower energy consumption.

Adsorption on a low-cost adsorbent is an attractive technology for water treatment ${ }^{21}$. Clay minerals, such as montmorillonite, vermiculite, and sepiolite, are of great interest in the study of adsorption for removing pollutants and as supporting materials for catalysts due to their peculiar physicochemical properties, as well as their abundance in nature, low costs, and environmentally friendliness. Among the clay mineral family, sepiolite $\left(\mathrm{Mg}_{8} \mathrm{Si}_{12} \mathrm{O}_{30}(\mathrm{OH})_{4}\left(\mathrm{OH}_{2}\right)_{4} \cdot 8 \mathrm{H}_{2} \mathrm{O}\right)$, with channels of molecular dimensions, determines that it may be considered an adsorbent with a uniform microporosity and external porosity ${ }^{22,23}$. These qualities make sepiolite have a huge specific surface area and high porosity, which can provide more reaction sites for catalytic activity and prevent nano-catalysts from aggregation ${ }^{24,25}$. Therefore, sepiolite has been employed as an adsorbent or support and binder for composites with metal oxides ${ }^{26}$. When catalysts are loaded on sepiolite, their catalytic activity, recyclability, and flexibility are further enhanced due to the unique structure and morphology of the sepiolite ${ }^{27}$.

The adsorption capacity that is restricted to an external surface can be enhanced using thermal or chemical modification, which are common methods for modifying clay minerals ${ }^{5}$. This modification can remove some impurities and increase the adsorption capacity of clay. Highly dispersed metal or metal oxide particles on a sepiolite support have shown improved catalytic activity in catalyzed processes, such as core-shell Ag@ $\mathrm{Pt}^{27}$, coprous oxide ${ }^{28}$, iron ${ }^{29}$, nickel $^{30}$, vanadium ${ }^{31}$, and $\mathrm{Ti}^{32}$ oxides. Among these metal oxides, Ag and Pt are noble metals that are restricted in application due to their high costs. Cuprous oxide/sepiolite can obtain an organic pollutant degradation rate of $87 \%$ under visible light, but the degradation time required is $5 \mathrm{~h}$. Ni is a group VIII metal, and Ni-based catalysts have received extensive attention due to their low costs and high activities in catalytic reactions. In addition, nickel oxide $(\mathrm{NiO})$ particles are very popular in coatings for the catalyst because of their high specific capacitance, inherent environmental friendliness, and practical accessibility ${ }^{33}$. Recently, natural sepiolite promoted with $\mathrm{Ni}$ has been used for the sustainable production of hydrogen and in the steam reformation of furfural and toluene. It has exhibited more enhanced catalytic performance than traditional $\mathrm{Ni}$ supports, such as $\mathrm{SiO}_{2}, \mathrm{MgO}$, or $\mathrm{Al}_{2} \mathrm{O}_{3}{ }^{34-36}$.

In this study, $\mathrm{NiO}$ /sepiolite materials with high adsorption and catalytic activities are synthesized via an impregnation route. The as-prepared samples are then characterized using X-ray diffractometry (XRD), scanning electron microscopy (SEM), Brunauer-Emmet-Teller (BET), thermogravimetric analysis (TGA). The adsorption of dye on the $\mathrm{NiO} /$ sepiolite and the subsequent high-temperature gas flow regeneration behavior are studied. In a single adsorption-regeneration unit, the $\mathrm{NiO}$ /sepiolite materials demonstrated excellent adsorption properties, as well as catalytic activities and thermal stabilities. In addition, the kinetics of the catalytic degradation of methylene blue over $\mathrm{NiO} /$ sepiolite is discussed. The regeneration temperature for the $\mathrm{NiO} /$ sepiolite materials was much lower than in our previous work ${ }^{19}$.

\section{Experiment}

Preparation of the NiO/sepiolite adsorbents/catalysts. The natural sepiolite was purchased from Henan Province (China). All of the chemical reagents were of analytical grade and used as received without further purification. Deionized water was used for all of the experiments. Prior to use, the raw sepiolite was pretreated and then placed into deionized water and stirred for $24 \mathrm{~h}$. Then, the sepiolite was filtered and rinsed three times using deionized water and dried at $105^{\circ} \mathrm{C}$ for $48 \mathrm{~h}$. Finally, the dried sepiolite was crushed. The NiO/sepiolite adsorbents/catalysts were prepared using impregnation. A typical synthesis procedure for the $\mathrm{NiO} /$ sepiolite was as follows: sepiolite with $40-60$ mesh was added to a $0.2 \mathrm{~mol} \mathrm{~L}^{-1}$ nickel nitrate solution and impregnated for $24 \mathrm{~h}$. The ratio of solid (sepiolite) to liquid (nickel nitrate solution) was 1:10. Then the solution was removed using filtration. The resulting granulated material was dried in an oven and subsequently calcined under an $\mathrm{O}_{2}$ flow at $350{ }^{\circ} \mathrm{C}$ for $1 \mathrm{~h}$ to obtain the $\mathrm{NiO} /$ sepiolite.

Characterization. A D8-Advance Bruker X-ray diffraction (XRD) powder diffractometer was used to study the crystalline phases of the $\mathrm{NiO} /$ sepiolite, in which $\mathrm{Cu}$ Karadiation was used. The chemical compositions of sepiolite and $\mathrm{NiO}$ /sepiolite were analysed by X-ray fluorescence (XRF, Rigaku XRF primus-2). A simultaneous differential thermal analysis/thermogravimetric (DTA/TG) system (Perkin-Elmer Pyris Diamond DTA/TG) was used for the thermogravimetric (TG) analysis of samples. The experiments were conducted at temperatures ranging from room temperature up to $1000^{\circ} \mathrm{C}$ in $\mathrm{O}_{2}$ gas. The specific surface area and pore structure of the $\mathrm{NiO} /$ sepiolite were obtained by determining nitrogen adsorption-desorption isotherms at $77 \mathrm{~K}$ on a Micromeritics ASAP 2020 apparatus. The morphologies of the samples were examined using a field emission scanning electron microscopy (FE-SEM, FEI Quanta 200 FEG).

Batch equilibrium adsorption experiments. Batch equilibrium adsorption experiments of a dye on the $\mathrm{NiO} /$ sepiolite were conducted. A known mass $(1 \mathrm{~g})$ of the $\mathrm{NiO} /$ sepiolite with $0.2 \mathrm{~L}$ of a methylene blue solution was stirred on a constant temperature shaker at $170 \mathrm{rpm}$. The concentrations of the dye were in the range of 50-350 $\mathrm{mg} \mathrm{L}^{-1}$. Samples were gathered at regular intervals and centrifugated, then the concentrations of the dye in the collected samples were analyzed using UV/Vis spectroscopy.

High-temperature gas flow regeneration. The regeneration of sepiolite and the $\mathrm{NiO} /$ sepiolite was conducted in an adsorption column with an inner diameter of $22 \mathrm{~mm}$ and a height of $400 \mathrm{~mm}$. A temperature control meter was used to control the regeneration temperature. One round of regeneration included the following procedures: 


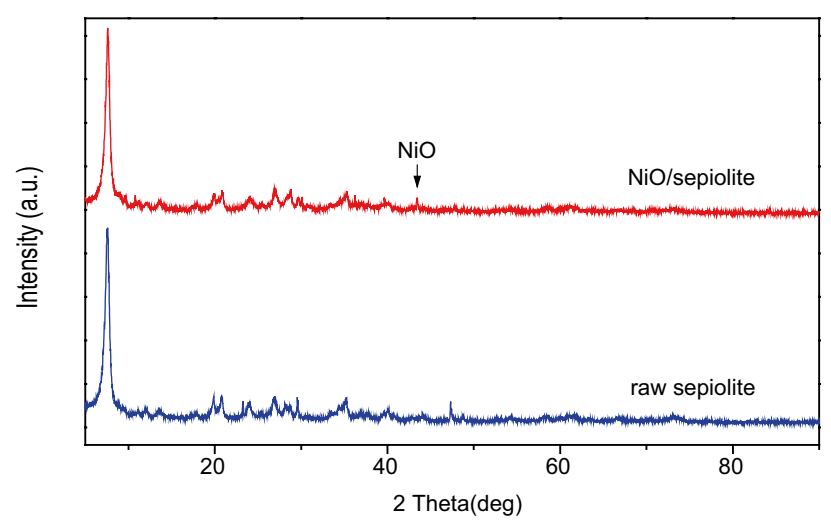

Figure 1. XRD patterns of $\mathrm{NiO}$-sepiolite and raw sepiolite.

\begin{tabular}{|l|l|l|l|l|l|l|l|}
\hline \multirow{3}{*}{ Sample } & \multicolumn{6}{|l|}{ Composition (wt. \%) } \\
\cline { 2 - 8 } & $\mathrm{SiO}_{2}$ & $\mathrm{MgO}$ & $\mathrm{CaO}$ & $\mathrm{Al}_{2} \mathrm{O}_{3}$ & $\mathrm{Fe}_{2} \mathrm{O}_{3}$ & $\mathrm{~K}_{2} \mathrm{O}$ & $\mathrm{NiO}$ \\
\hline Sepiolite & 55.0505 & 33.5735 & 11.1359 & 0.1749 & 0.0468 & 0.0185 & - \\
\hline $\mathrm{NiO} /$ sepiolite & 52.4350 & 30.8792 & 14.2931 & 0.2367 & 0.0528 & - & 2.1032 \\
\hline
\end{tabular}

Table 1. Chemical composition of sepiolite and $\mathrm{NiO} /$ sepiolite (derived from XRF analysis).

(i) Initial adsorption: A certain mass of sepiolite or $\mathrm{NiO} /$ sepiolite was added to the adsorption column, and a solution of methylene blue was pumped into the adsorption column using a peristaltic pump until the effluent concentration was greater than the penetration point. The initial adsorbent loading qi was then determined.

(ii) High-temperature gas flow regeneration: Once the initial adsorption ended, the regeneration started. Oxygen was used as the oxidation gas to regenerate the $\mathrm{NiO}$ /sepiolite adsorbed with methylene blue at the same time that the methylene blue was degraded. The $\mathrm{O}_{2}$ gas flow was supplied using an air compressor at the bottom of the adsorption column during regeneration. The regeneration temperature was $350{ }^{\circ} \mathrm{C}$. The catalytic activity of $\mathrm{NiO} /$ sepiolite was evaluated by regeneration rate.

(iii) Re-adsorption: A fresh solution of methylene blue was added to the adsorption column to be absorbed by the regenerated sepiolite or $\mathrm{NiO}$ /sepiolite. The adsorption process was similar to that of step (i). After adsorption, the regenerated sepiolite or $\mathrm{NiO} /$ sepiolite loading qr was determined, at this time, the regeneration rate was calculated. The regeneration rate was calculated by following Eq. $(1)^{7}$ :

$$
\text { Regeneration rate }(\%)=(\mathrm{qi} / \mathrm{qr}) \times 100 \%
$$

where $\mathrm{qr}(\mathrm{mg} / \mathrm{g})$ and qi $(\mathrm{mg} / \mathrm{g})$ are the equilibrium adsorption capacity of the new and regenerated materials, respectively.

The schematic of adsorption-regeneration cycle system is shown in Schematic 1 (Supplementary Figure), which shows one round of regeneration.

\section{Results and discussion}

Physico-chemical properties. The physico-chemical properties of $\mathrm{NiO}$ /sepiolite was characterized. X-ray diffractograms for $\mathrm{NiO}$-sepiolite and raw sepiolite are present in Fig. 1. The main diffraction peaks located at $2 \theta=7.4^{\circ}, 20.7^{\circ}, 23.9^{\circ}, 26.8^{\circ}, 28.3^{\circ}, 35.1^{\circ}, 40.1^{\circ}$ and $47.3^{\circ}$ correspond to the characteristic peaks of raw sepiolite. The peak at $2 \theta=29.4^{\circ}$ is possibly attributed to the characteristic peak of calcium carbonate (JCPDS, No. $86-0174)^{27}$. The peak located at $2 \theta=43.4^{\circ}$ belongs to the NiO (JCPDS, No. 73-1519), the signal of $2 \theta=37.2^{\circ}$ is not visible because of the low content of $\mathrm{Ni}$ in the composite. Some relative peaks of sepiolite in $\mathrm{NiO} /$ sepiolite is slightly lower than that of the raw one, probably due to the $\mathrm{NiO}$ particles deposition. The chemical compositions of sepiolite and $\mathrm{NiO} /$ sepiolite are analysed by XRF and the results are listed in Table 1 . We can see that the amount load of $\mathrm{NiO}$ is $2.1032 \%$ from the XRF analysis, which is in agreement with the XRD result that the signal of $2 \theta=37.2^{\circ}$ is not obvious.

The SEM images of natural sepiolite, $\mathrm{NiO} /$ sepiolite, regenerated sepiolite, and regenerated $\mathrm{NiO} /$ sepiolite are shown in Fig. 2a-d, respectively. These images show that these samples have fibrous structures. While natural sepiolite (Fig. 2a) agglomerates badly, after regeneration using a high-temperature gas flow, a certain number of cracks were observed. This was likely due to the tension forces generated by the gas flow. Another reason might have been because the process of high-temperature gas flow regeneration is equal to another heat treatment process (Fig. 2c). The fibers of the $\mathrm{NiO}$ /sepiolite are longer than those of the natural sepiolite, and some 

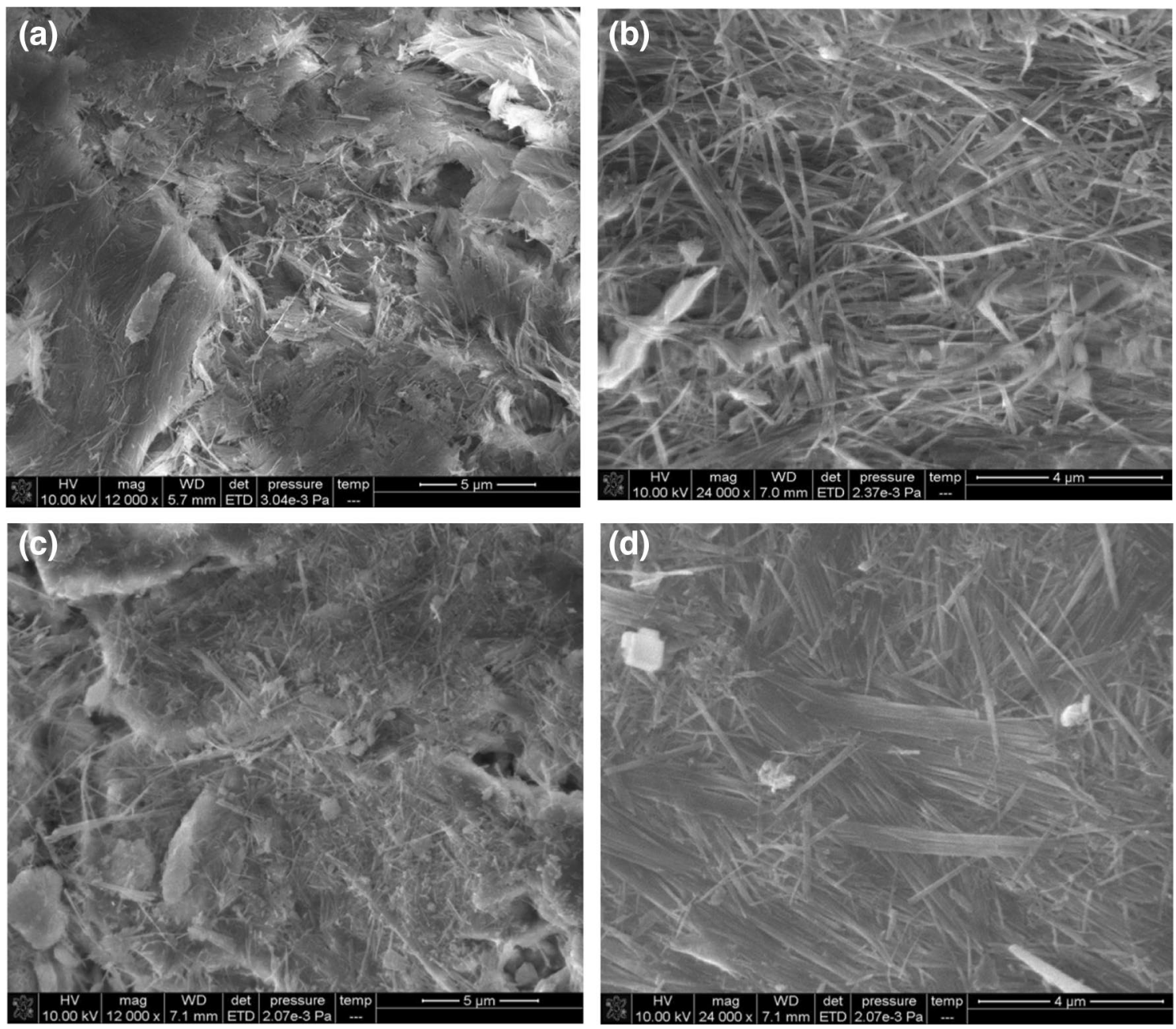

Figure 2. SEM images of sepiolite (a), NiO/sepiolite (b), regenerated sepiolite (c) and regenerated $\mathrm{NiO} /$ sepiolite (d).

particles aggregated and covered the surface of the fibers (Fig. 2b). The regenerated NiO/sepiolite (Fig. 2d) still maintained the fibrous morphology, although some fibers broke into pieces or granular materials, indicating the modified sepiolite materials had good thermal stability and mechanical strength during high-temperature gas flow regeneration. The results of the SEM detection indicated that the $\mathrm{NiO} /$ sepiolite was more stable than sepiolite under tension forces and heat treatment during sample preparation and regeneration.

The BET experiment was performed to confirm the presence of the porous structure in the catalyst and determine the surface area, as well as the pore size distribution. The BET specific surface area of the natural sepiolite and the $\mathrm{NiO} /$ sepiolite was calculated to be 87.7 and $150.6 \mathrm{~m}^{2} \mathrm{~g}^{-1}$, respectively, from the nitrogen adsorption isotherm data given in Fig. 3a,b. Both of the $\mathrm{N}_{2}$ adsorption-desorption isotherms of the natural sepiolite (Fig. 3a) and the $\mathrm{NiO} /$ sepiolite (Fig. $3 \mathrm{~b}$ ) belonged to type IV isotherms with a hysteresis loop. This was due to the presence of the inhomogeneous mesopores. The Barrett-Joyner-Halenda (BJH) pore size distribution curves calculated from the desorption branch are shown in the insets of Fig. 3a,b. The pore size distribution graphs confirmed that the pore size distributions of the two samples were approximately located at $3.8 \mathrm{~nm}$ and $19.9 \mathrm{~nm}$, and both of them contained mesopores $(20 \AA<$ pore width $<500 \AA$ ). It was demonstrated that the loading of $\mathrm{NiO}$ affected the sepiolite structure, and both $\mathrm{S}_{\mathrm{BET}}$ and the pore size increased significantly. A larger specific surface area can provide much more active sites and adsorption interfaces for the adsorption and catalytic degradation of pollutants ${ }^{27}$.

As a thermal analysis (TA) technique, thermogravimetry/derivative thermogravimetry (TG/DTG) has been used to investigate the thermal behavior of compounds and the effect of a catalyst on the catalytic degradation of pollutants. Figure $4 \mathrm{a}-\mathrm{c}$ shows the TG/DTG curves of methylene blue, $\mathrm{NiO}$ /sepiolite and $\mathrm{NiO} /$ sepiolite adsorbed with methylene blue, respectively. The removal of adsorbed water from the external surface of the methylene blue was completed up to $100{ }^{\circ} \mathrm{C}$ with a $15 \%$ weight loss (Fig. 4a). When increasing the temperature from 100 to $400{ }^{\circ} \mathrm{C}$, a weight loss of approximately $50 \%$ was observed. This was ascribed to the combustion of organic matter, and it showed a significant decomposition at $400{ }^{\circ} \mathrm{C}$. Then the decomposition process ended at $600{ }^{\circ} \mathrm{C}$. Figure $4 \mathrm{~b}$ shows the TG/DTG curves of the $\mathrm{NiO} /$ sepiolite. The adsorbed water on the surface of the sepiolite was removed at $100{ }^{\circ} \mathrm{C}$ with a $3 \%$ weight loss. The first portion of the bound water left the structure at $250-300{ }^{\circ} \mathrm{C}$, with a weight loss of $1 \%{ }^{37}$. The zeolitic water in the channel-type voids of the structure was not found because 
(a)

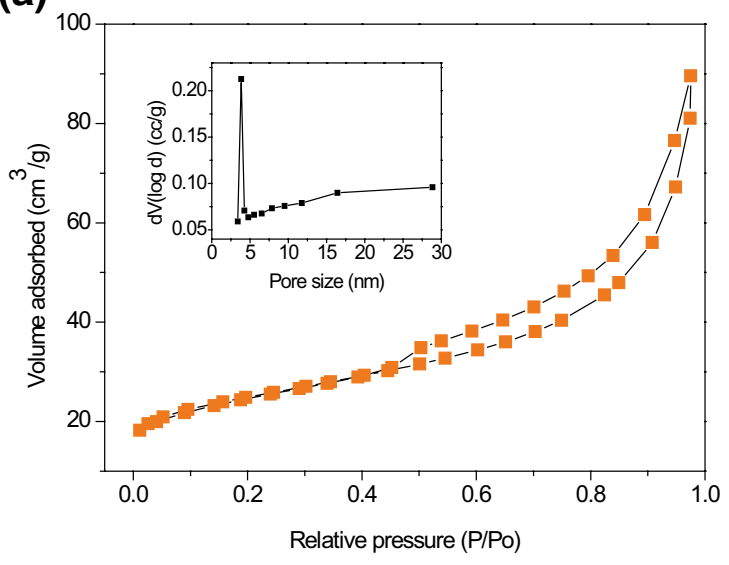

(b)

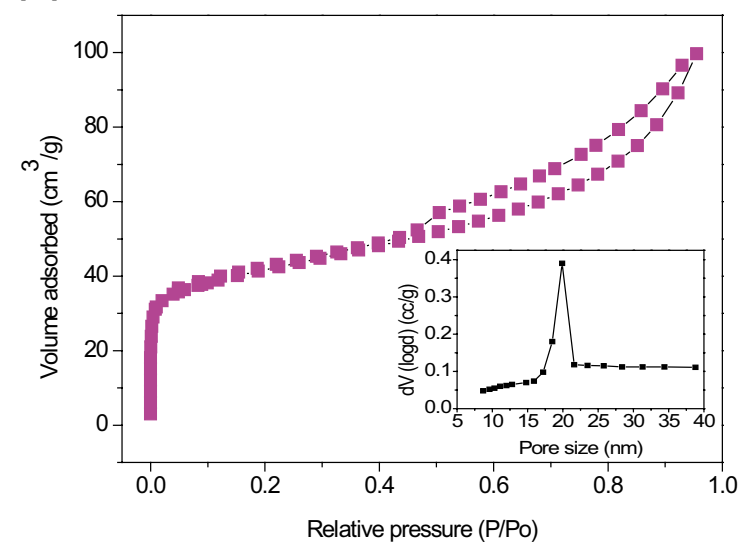

Figure 3. BJH nitrogen adsorption-desorption isotherms of raw sepiolite (a), and $\mathrm{NiO} /$ sepiolite (b), the inset are the corresponding pore size distribution plots.

the $\mathrm{NiO} /$ sepiolite was calcined at $350^{\circ} \mathrm{C}$ during sample preparation. The second portion of the bound water began to leave the structure at a higher temperature. The remaining bound water was removed at $750{ }^{\circ} \mathrm{C}$ and was accompanied by a $14 \%$ additional weight loss. Figure $4 \mathrm{c}$ shows the TG/DTG curves of the NiO/sepiolite adsorbed with the methylene blue. This TG/DTG curve shows an obvious $2 \%$ weight loss at $350{ }^{\circ} \mathrm{C}$ ascribed to the decomposition of the methylene blue. The degradation temperature was significantly changed during the presence of the catalyst, lowering the degradation temperature from 400 to $350^{\circ} \mathrm{C}$. It was clear that the modified sepiolite was useful to induce the oxidation of organic matter. Salvador et al. also reported that NiOx-modified sepiolite could effectively induce dehydrohalogenation and oxidation of a chlorinated pesticide (Lindane) ${ }^{38}$.

Adsorption. The adsorption capacity and temperature are the most important characteristics in the determination of the adsorption efficiency of $\mathrm{NiO} /$ sepiolite. Typically, during the liquid phase, adsorption is endothermic. Increasing the temperature can increase the rate of diffusion of adsorbate molecules across the external boundary layer and in the internal pores of the adsorbent particle, causing the viscosity of the solution to decrease $^{39}$. Adsorption isotherms of the $\mathrm{NiO} /$ sepiolite were examined at $298 \mathrm{~K}, 308 \mathrm{~K}$, and $318 \mathrm{~K}$, and the corresponding results are displayed in Fig. 5a. The results showed that the temperature had a great influence on the adsorption capacity, which increased with an increase in the temperature, and it was an endothermic process. Langmuir models were used to attempt to fit isotherms, and the results are presented in Fig. 5b. The correlation coefficients at the temperatures of 298,308 , and $318 \mathrm{~K}$ were $0.9977,0.9981$, and 0.9984 , respectively, suggesting that the adsorption isotherm data followed the Langmuir model. Based on the Langmuir isotherm, the maximal absorption capacities of the $\mathrm{NiO} /$ sepiolite materials were $50,39.06$, and $22.73 \mathrm{mg} / \mathrm{g}$ at the temperatures of 318,308 , and $298 \mathrm{~K}$, respectively. The adsorption isotherm study indicated that the $\mathrm{NiO} /$ sepiolite exhibited a high adsorption potential for the removal of methylene blue from an aqueous solution. These results show that temperature has a great influence on adsorption capacity, which increases with the increase of temperature, it is an endothermic process. Freundlich and Langmuir models are used to fit isotherms. The results of Freundlich and Langmuir models analyses suggest that adsorption isotherm data follow the Langmuir model (data about Freundlich model fitting is not showed). The fitting results are presented in Fig. 5b and Table 2. The adsorption isotherm study indicates that $\mathrm{NiO}$ /sepiolite exhibits a high adsorption potential for the removal of methylene blue from aqueous solution.

Regeneration. The $\mathrm{NiO} /$ sepiolite was regenerated by high-temperature gas flow, and the effect of the regeneration temperature and the volume fraction of $\mathrm{O}_{2}$ on the regeneration rate were studied. Temperature is one of the most important factors in high-temperature gas flow regeneration. The effect of the regeneration temperature on the regeneration rate was studied using a simultaneous DTA/TG system. Methylene blue adsorbed on the $\mathrm{NiO} /$ sepiolite was oxidized by oxygen with volume fraction of $50 \%$ and a gas flow rate of $6 \mathrm{~L} / \mathrm{min}$ at different temperatures $\left(350{ }^{\circ} \mathrm{C}, 375^{\circ} \mathrm{C}\right.$, and $\left.400{ }^{\circ} \mathrm{C}\right)$. When the temperature rose to the set value, it was kept constant to record the TG data. The TG curves obtained from the degradation of methylene blue adsorbed on the $\mathrm{NiO} /$ sepiolite at different temperatures are shown in Fig. 6a. As expected, the order of the weight loss rates was $400{ }^{\circ} \mathrm{C}>375^{\circ} \mathrm{C}>350^{\circ} \mathrm{C}$. It is apparent that higher temperatures were beneficial for the degradation of dye and regeneration of $\mathrm{NiO} /$ sepiolite. At $350{ }^{\circ} \mathrm{C}$, it was observed that catalysts adsorbed with the dye showed no more weightlessness until $18 \mathrm{~min}$, and the mass loss (4\%) was in a good agreement with the saturated adsorption amount of methylene blue on the $\mathrm{NiO} /$ sepiolite $(39.06 \mathrm{mg} / \mathrm{g})$. The mass loss was due to the complete degradation of the dye. In addition, the catalysts achieved complete regeneration. At $375^{\circ} \mathrm{C}$, the removal of dye was completed at $14 \mathrm{~min}$, with a mass loss of approximately $3.47 \%$. With a higher degradation temperature at $400{ }^{\circ} \mathrm{C}$, the complete removal of the dye was completed at $9 \mathrm{~min}$. This was accompanied by an approximate $3.3 \%$ weight loss. At $400{ }^{\circ} \mathrm{C}$, the weight loss had no change compared with that of the two other lower temperatures with relatively short time periods. It is noteworthy that the weight loss decreased with an increase in the temperature due to the 

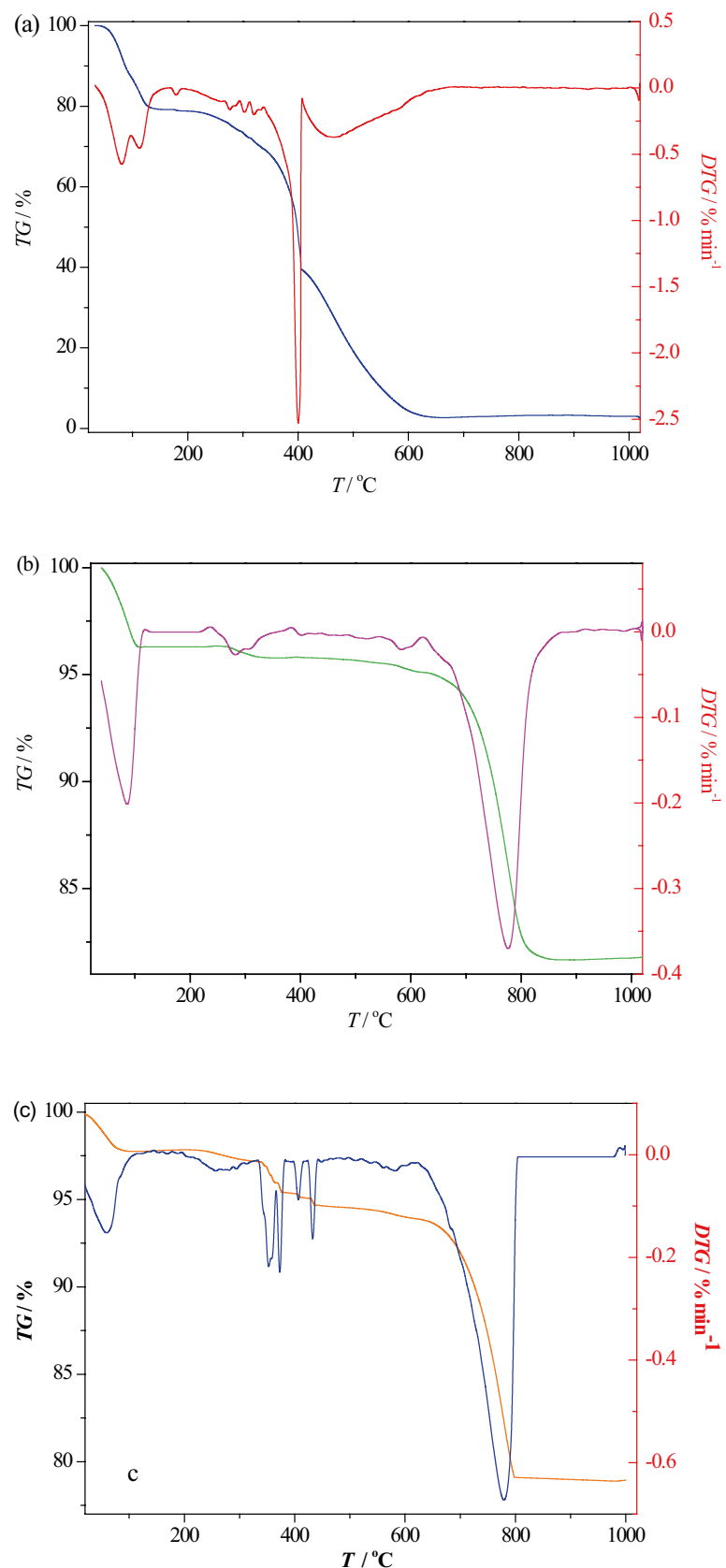

Figure 4. TG/DTG curves of methylene blue (a), $\mathrm{NiO} /$ sepiolite (b) and $\mathrm{NiO} /$ sepiolite adsorbed with methylene blue (c) under $20 \mathrm{~cm}^{3} / \mathrm{min}$ of $\mathrm{O}_{2}$ (heating rate $=10^{\circ} \mathrm{C} / \mathrm{min}$ ).

degradation of more dye when the temperature increased from 350 to $400{ }^{\circ} \mathrm{C}$. Hence, the regeneration of $\mathrm{NiO} /$ sepiolite was favored at higher temperatures.

The effect of the volume fraction of $\mathrm{O}_{2}$ on the regeneration rate was also studied using the simultaneous DTA/ TG system. The methylene blue that adsorbed on the $\mathrm{NiO} /$ sepiolite was oxidized by oxygen with volume fractions of $21 \%, 50 \%$ and $99.5 \%$, the gas flow rate was $6 \mathrm{~L} / \mathrm{min}$, and the temperature was maintained at $350{ }^{\circ} \mathrm{C}$ to record the TG data. The results are shown in Fig. 6b. It can be seen from Fig. $6 \mathrm{~b}$ that the $\mathrm{NiO} /$ sepiolite catalysts required 7,18 and $32.5 \mathrm{~min}$ to reach the end of regeneration, when the volume fractions of oxygen were $99.5 \%, 50 \%$ and $21 \%$, respectively. These results illustrated that the regeneration efficiency was strongly oxygen concentrationdependent, the oxidation ability of $\mathrm{O}_{2}$ was related to its volume fraction, and it showed a stronger oxidation ability by increasing the volume fraction accordingly, and these factors favored the regeneration of the $\mathrm{NiO} /$ sepiolite.

In summary, the thermal studies were significantly helpful to understand the thermal behavior of the compounds. In addition, they illuminated the influences of the regeneration temperature and volume fraction of $\mathrm{O}_{2}$ on the regeneration rate. The degradation rate of the dye and the regeneration of catalysts were strongly dependent on the process temperature and volume fraction of $\mathrm{O}_{2}$. 

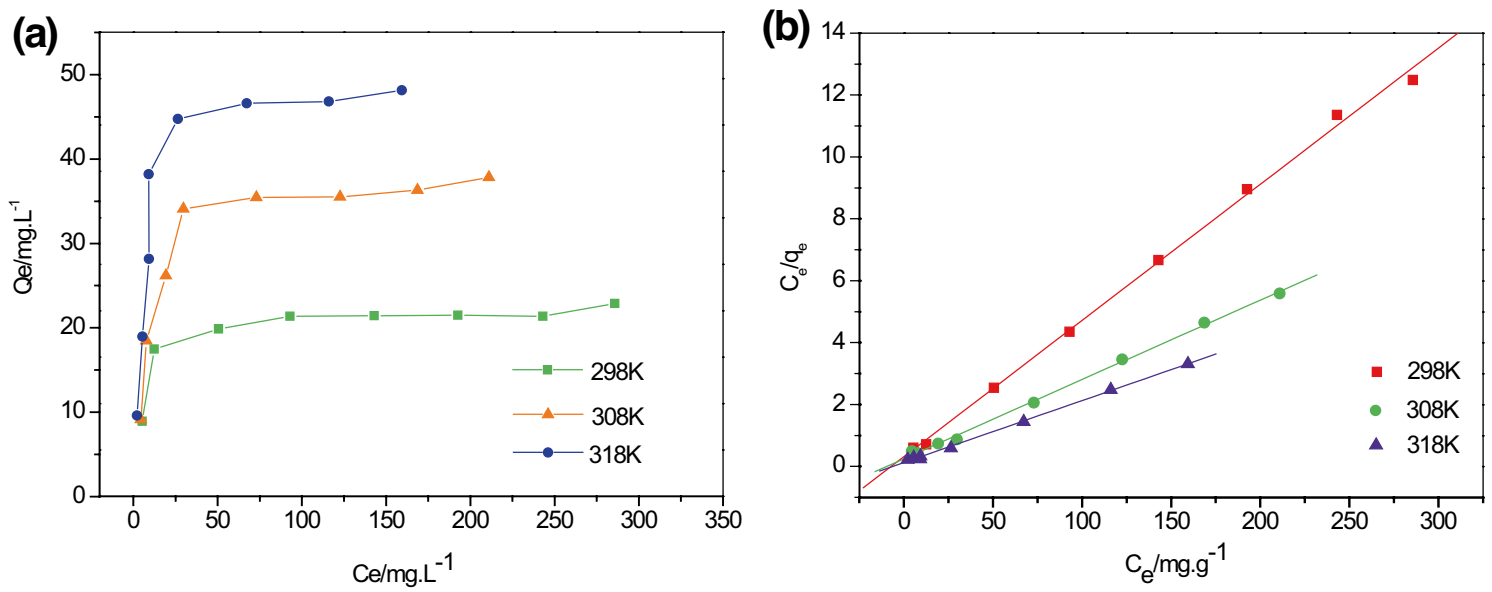

Figure 5. Adsorption isotherms $\mathrm{NiO}$ /sepiolite (a), isothermal adsorption of $\mathrm{NiO}$ /sepiolite: filled circles represent experimental data and the line represents the simulated Langmuir model (b).

\begin{tabular}{|l|l|l|l|}
\hline \multirow{2}{*}{ Temperature/K } & \multicolumn{3}{|l|}{ Langmuir isotherm $\frac{C_{e}}{q_{e}}=\frac{C_{e}}{q_{m}}+\frac{1}{q_{m} K_{L}}$} \\
\cline { 2 - 4 } & $\mathbf{q}_{\mathbf{m}}\left(\mathbf{m g ~ g}^{-1}\right)$ & $\mathbf{K}_{\mathbf{L}}\left(\mathbf{d m}^{3} \mathbf{m g}^{-1}\right)$ & $\mathbf{R}^{2}$ \\
\hline 298 & 22.73 & 0.1388 & 0.9977 \\
\hline 308 & 39.06 & 0.1047 & 0.9981 \\
\hline 318 & 50.00 & 0.1609 & 0.9984 \\
\hline
\end{tabular}

Table 2. Langmuir parameters and correlation coefficients for methylene blue adsorption onto NiO/sepiolite.
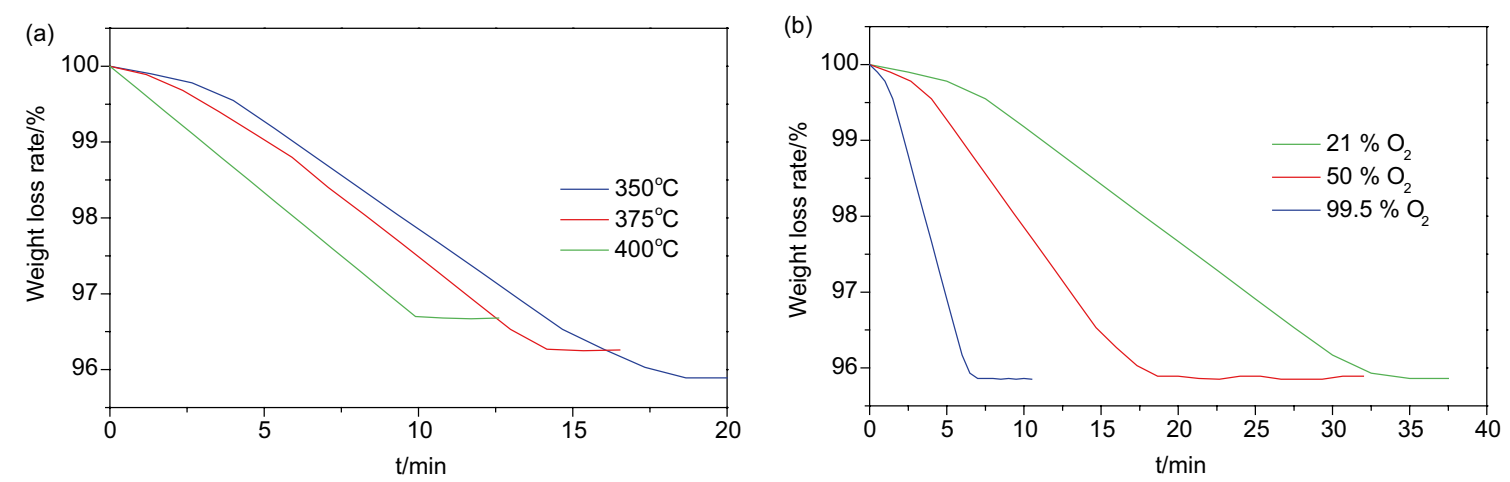

Figure 6. TG curves obtained in the degradation of methylene blue adsorbed on $\mathrm{NiO} /$ sepiolite at different temperature (a). TG curves obtained in the degradation of methylene blue adsorbed on $\mathrm{NiO} /$ sepiolite at different volume fraction of $\mathrm{O}_{2}(\mathbf{b})$.

We also studied the stability of $\mathrm{NiO} /$ sepiolite. Figure 7 a shows the regeneration rate over four cycles of adsorption and high-temperature gas flow regeneration for removing dye using $\mathrm{NiO}$ /sepiolite or natural sepiolite. $\mathrm{NiO} /$ sepiolite was found to be sufficient for achieving a $74 \%$ regeneration rate, delivering a significantly higher regeneration rate compared to that of natural sepiolite at $48.5 \%$. In the case of $\mathrm{NiO} /$ sepiolite, the regeneration rate was still nearly the same as the first time, which was attributed to its modification treatment. After four circulations, the regeneration rate of $\mathrm{NiO} /$ sepiolite was $63.26 \%$, while that of raw sepiolite was $30.76 \%$. This indicated that the catalytic activity of $\mathrm{NiO} /$ sepiolite was much higher than that of natural sepiolite. The process of adsorption of dye on $\mathrm{NiO}$ /sepiolite and its regeneration by high-temperature gas flow is showed in Fig. 7b, first, the dye was adsorbed on the surface of $\mathrm{NiO}$ /sepiolite, then the $\mathrm{NiO}$ /sepiolite adsorbed with dye was regenerated by hightemperature gas flow and reused.

Reaction kinetics. The reaction kinetics was obtained by a series of experiments. First, we determine the reaction order. In the initial stage of the regeneration process of $\mathrm{NiO} /$ sepiolite under $\mathrm{O}_{2}$ atmosphere, the reaction gas $\mathrm{O}_{2}$ is uniformly distributed inside the particles, which can be described by a uniform reaction model ${ }^{40-42}$. 
(a)

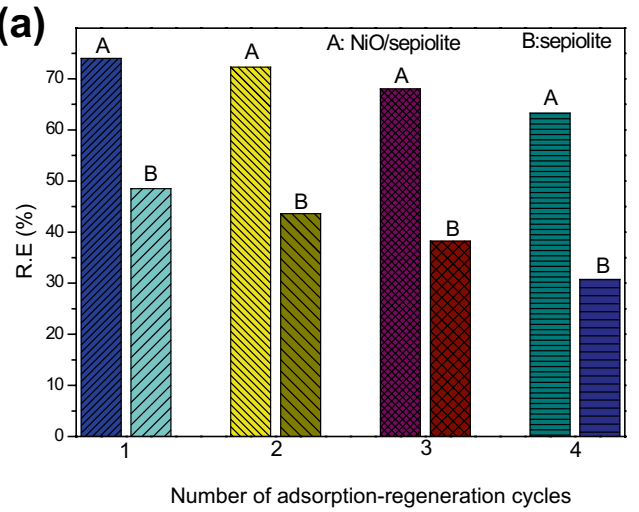

(b)

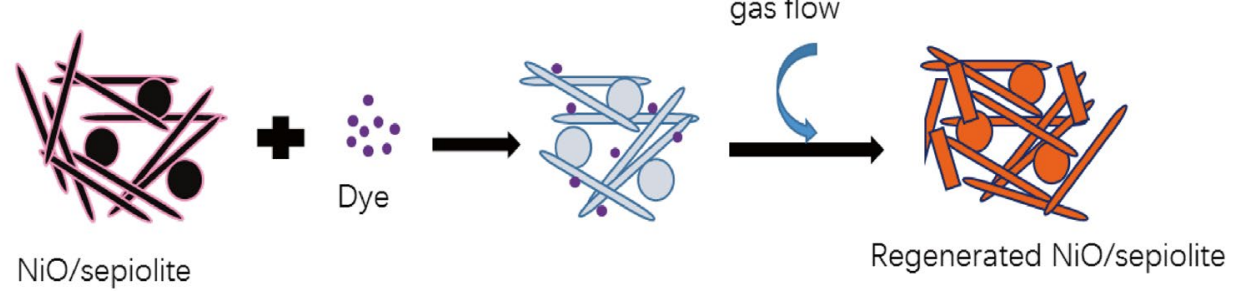

Figure 7. Regeneration rate over four cycles of adsorption and regeneration for removal of dye from aqueous solution using $\mathrm{NiO} /$ sepiolite and sepiolite (a), Schematic diagram of the adsorption and high-temperature gas flow regeneration process on $\mathrm{NiO} /$ sepiolite $(\mathbf{b})$.

The regeneration reaction order is obtained by the average reaction rate under different $\mathrm{O}_{2}$ volume fractions. The uniform reaction model is expressed as the following Eq. $(2)^{42}$ :

$$
\frac{\mathrm{d} X}{\mathrm{~d} t}=k(1-X) C_{O_{2}}^{n}
$$

where $\mathrm{X}$ is the regeneration rate of $\mathrm{NiO}$ /sepiolite, $\mathrm{t}$ is time $(\mathrm{s}), \mathrm{k}$ is the reaction rate constant, $\mathrm{C}_{\mathrm{O}_{2}}$ is the concentration of $\mathrm{O}_{2}\left(\mathrm{~mol} \mathrm{~cm}^{-3}\right)$, and $\mathrm{n}$ is the reaction order. Woods et al. also used this expression to obtain the kinetic equation of $\mathrm{ZnO}-\mathrm{TiO}_{2}$ adsorbents ${ }^{43,44}$. This uniform reaction model expression can be transformed into the following Eq. (3) by logarithm:

$$
\frac{\mathrm{d} X}{\mathrm{~d} t(1-X)}=\ln k+n \ln C_{\mathrm{O}_{2}}
$$

The reaction order $\mathrm{n}$ can be determined by the TGA data from 350 to $400{ }^{\circ} \mathrm{C}$ (Fig. 6a,b), and we assume that the order of $\mathrm{O}_{2}$ in regeneration reaction to be 1 , that is, $\mathrm{n}=1$, this value is substituted into Eq. (3), and calculate three different points according to Fig. 6a,b, then drawing the relationship between the regeneration rate of $\mathrm{NiO} /$ sepiolite and $\mathrm{O}_{2}$ content, the results are showed in Fig. 8a. We can see that the slope (n) is 1.0248, the correlation coefficient $(\mathrm{R})$ is 0.9905 , the results show that the assumption of reaction order $\mathrm{n}$ is reasonable, therefore, the reaction order of regeneration under $\mathrm{O}_{2}$ is a first-order reaction, the kinetic equation can be expressed as the following Eq. (4):

$$
-r=\frac{\mathrm{d} X}{\mathrm{~d} t}=k(1-X) C_{O_{2}}
$$

Second, we work out the apparent kinetics parameters. The kinetic behavior of the regeneration reaction could be described by the equivalent particle model. This model parameters are described as the following Eqs. (5), (6) and (7):

$$
\begin{gathered}
t=A G(X) \\
G(X)=1-(1-X)^{1 / 2} \\
A=\rho_{o} R_{o} / k C_{O_{2}}
\end{gathered}
$$



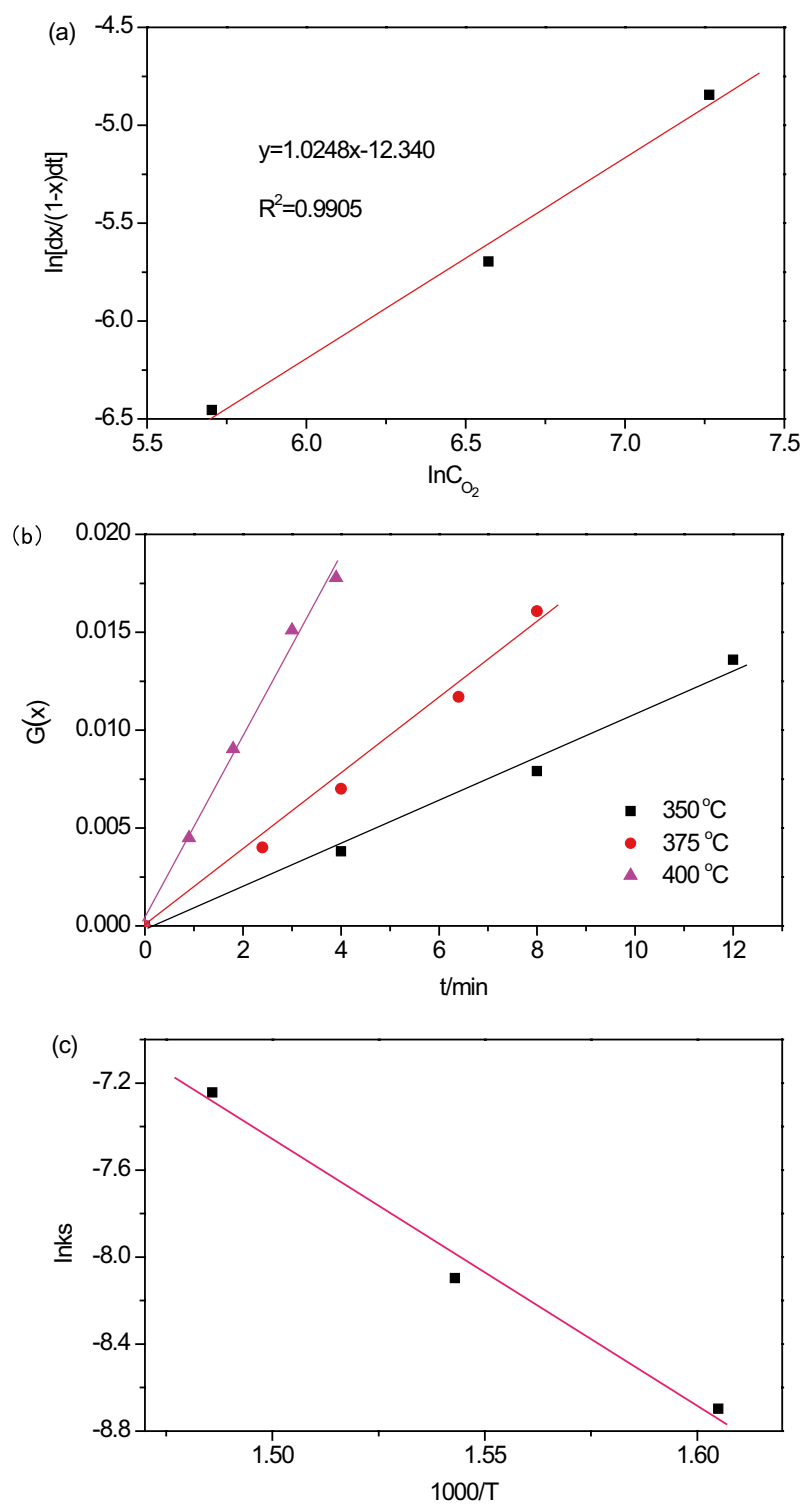

Figure 8. The relationship between the regeneration rate of $\mathrm{NiO} /$ sepiolite and $\mathrm{O}_{2}$ content (a), relationship between $\mathrm{G}(\mathrm{x})$ and $\mathrm{t}(\mathbf{b})$, relationship between $\operatorname{lnk}$ and $1 / \mathrm{T}(\mathbf{c})$.

\begin{tabular}{|l|l|l|l|}
\hline Temperature $\left({ }^{\circ} \mathbf{C}\right)$ & $\mathrm{G}(\mathrm{x})$-t fitting equation & $\mathbf{k}$ & $\mathbf{R}^{\mathbf{2}}$ \\
\hline 350 & $\mathrm{G}(\mathrm{x})=0.0011 \mathrm{t}-0.0005$ & $1.67 \times 10^{-4}$ & 0.9949 \\
\hline 375 & $\mathrm{G}(\mathrm{x})=0.0020 \mathrm{t}-0.0005$ & $3.04 \times 10^{-4}$ & 0.9921 \\
\hline 400 & $\mathrm{G}(\mathrm{x})=0.0047 \mathrm{t}-0.0003$ & $7.15 \times 10^{-4}$ & 0.9937 \\
\hline
\end{tabular}

Table 3. The curve fitting of $\mathrm{G}(\mathrm{x})-\mathrm{t}$ and relevant parameters.

where $G(x)$ is the characteristic function of surface reaction control, $X$ is the regeneration rate, $t$ is time (s), $\mathrm{k}$ is the reaction rate constants, $\mathrm{R}_{\mathrm{o}}$ is the radius of particle $\left(3 \times 10^{-3} \mathrm{~m}\right), \mathrm{Co}_{2}$ is the mass concentration of $\mathrm{O}_{2}$ $\left(7.14 \times 10^{2} \mathrm{~g} \mathrm{~m}^{-3}\right), \rho_{\mathrm{o}}$ is the grain density of dye $\left(3.62 \times 10^{4} \mathrm{~g} \mathrm{~m}^{-3}\right)$. On the basis of data obtained at $50 \% \mathrm{O}_{2}$ (volume fraction, reaction at 350,375 and $400{ }^{\circ} \mathrm{C}$ ), the values of $\mathrm{G}(\mathrm{x})$ under different regeneration rate are calculated according to Eqs. (5), (6) and (7), and the results are shown in Fig. 8b, the fitting results are listed in Table 3. From Table 3 we can see that the reaction rate constants $\mathrm{k}$ increase with the increase of regeneration temperature, this means that as the reaction temperature increases, the reaction rate also increases. All of the correlation coefficient $\mathrm{R}^{2}$ are above 0.99 .

After taking logarithm, the Arrhenius equation (Eq. 8) can be transformed into Eq. (9). 


$$
\begin{aligned}
& k=A \exp \left(-E_{a} / R T\right) \\
& \ln k=-\frac{E_{a}}{R T}+\ln A
\end{aligned}
$$

where $\mathrm{A}$ is the pre-exponential factor, $k$ is the reaction rate constant, Ea is the activation energy $\left(\mathrm{kJ} \mathrm{mol}^{-1}\right), \mathrm{R}$ is the gas constant $\left(8.314 \mathrm{~J} \mathrm{~mol}^{-1} \mathrm{~K}^{-1}\right)$, $\mathrm{T}$ is the absolute temperature $(\mathrm{T})$. When plotting of lnk with $1 / \mathrm{T}$ ( showed in Fig. 8c), the fitting equation is $\operatorname{lnk}_{\mathrm{s}}=-12.172 \times(1000 / \mathrm{T})+10.789$, the pre-exponential factor $\mathrm{A}$ is $4.85 \times 10^{4} \mathrm{~m} \mathrm{~s}^{-1}$, the activation energy $\mathrm{Ea}$ is $101.20 \mathrm{~kJ} \mathrm{~mol}^{-1}$, which indicates that the regeneration reactivity is quite sensitive to temperature ${ }^{42}$. Therefore, the Eq. (4) can be transformed into Eq. (10), which is the apparent kinetic reaction of regeneration reaction under high-temperature gas flow.

$$
-r=\exp \left(\frac{12.172 \times 10^{3}}{T}+10.789\right)(1-X) C_{O_{2}}
$$

\section{Conclusions}

In summary, $\mathrm{NiO}$ /sepiolite materials were prepared using impregnation, and this was found to be an efficient adsorbent and active catalyst for removing dye in an adsorption-high-temperature gas regeneration single unit. The degradation temperature of the dye observed in the presence of the $\mathrm{NiO} /$ sepiolite was much lower than that with no catalyst. This catalyst had a high regeneration rate of $74 \%$ within only 7 min under an $\mathrm{O}_{2}$ gas flow. The reusability of the catalyst after regeneration was then investigated. The degradation rate of the dye adsorbed on the $\mathrm{NiO} /$ sepiolite and/or the regeneration of the catalysts were strongly influenced by the regeneration temperature and the volume fraction of $\mathrm{O}_{2}$. The reaction kinetic experiments demonstrated that the reaction order was 1 . These adsorption and regeneration processes successfully eliminated organic pollutants. This study demonstrated the effectiveness of high-temperature gas degradation for dye, providing an efficient approach for the treatment of wastewater and regeneration of adsorbents and catalysts.

Received: 20 October 2021; Accepted: 1 February 2022

Published online: 21 February 2022

\section{References}

1. Wu, X., Zhang, Q., Liu, C., Zhang, X. \& Chung, D. D. L. Carbon-coated sepiolite clay fibers with acid pre-treatment as low cost organic adsorbents. Carbon 123, 259-272. https://doi.org/10.1016/j.carbon.2017.07.063 (2017).

2. Basnet, P., Samanta, D., Chanu, T. I. \& Chatterjee, S. Visible light facilitated degradation of alternate dye solutions by highly reusable Mn-ZnO nanophotocatalyst. J. Alloy Compd. 867, 158870. https://doi.org/10.1016/j.jallcom.2021.158870 (2021).

3. Arenberg, M. R. \& Arai, Y. Efficient self-photo-degradation of cationic textile dyes involved triethylamine and degradation pathway. Chemosphere 266, 129209. https://doi.org/10.1016/j.chemosphere.2020.129209 (2021).

4. Gong, Y., Quan, X., Yu, H. \& Chen, S. Synthesis of Z-scheme $\mathrm{Ag}_{2} \mathrm{CrO}_{4} / \mathrm{Ag} / \mathrm{g}-\mathrm{C}_{3} \mathrm{~N}_{4}$ composite with enhanced visible-light photocatalytic activity for 2, 4-dichlorophenol degradation. Appl. Catal. B-Environ. 219, 439-449. https://doi.org/10.1016/j.apcatb.2017. 07.076 (2017).

5. Yu, H., Zhu, Y. F., Xu, J. \& Wang, A. Q. Fabrication porous adsorbents template from modified sepiolite-stabilized aqueous foams for high efficient removal of cationic dyes. Chemosphere 259, 126949. https://doi.org/10.1016/j.chemosphere.2020.126949 (2020).

6. Garcia-Rodriguez, O. et al. Impact of the saturation level on the electrochemical regeneration of activated carbon in a single sequential reactor. Carbon 163, 265-275. https://doi.org/10.1016/j.carbon.2020.02.041 (2020).

7. Asghar, H. M., Hussain, S. N., Roberts, E. P., Campen, K. \& Brown, N. W. Pre-treatment of adsorbents for waste water treatment using adsorption coupled-with electrochemical regeneration. J. Ind. Eng. Chem. 19, 1689-1696. https://doi.org/10.1016/j.jiec.2013. 02.007 (2013).

8. Zhou, L. et al. Regeneration of activated carbon air-cathodes by half-wave rectified alterating in microbial fuel cells. Appl. Energy 219, 199-206. https://doi.org/10.1016/j.apenergy.2018.03.022 (2018).

9. Palas, B., Ersoz, G. \& Atalay, S. Catalytic wet air oxidation of Reactive Black 5 in the presence of $\mathrm{LaNiO}_{3}$ perovskite catalyst as a green process for azo dye removal. Chemosphere 209, 823-830. https://doi.org/10.1016/j.chemosphere.2018.06.151 (2018).

10. Costa, L. R. D., Ribeiro, L. D., Hidalgo, G. E. N. \& Feris, L. A. Evaluation of efficiency and capacity of thermal, chemical and ultrasonic regeneration of tetracycline exhausted activated carbon. Environ. Technol. https://doi.org/10.1080/09593330.2020.1811391 (2020).

11. Larasati, A., Fowler, G. D. \& Graham, N. J. D. Chemical regeneration of granular activated carbon: preliminary evaluation of alternative regenerant solutions. Environ. Sci. Water Res. 6, 2043-2056. https://doi.org/10.1039/d0ew00328j (2020).

12. Park, J. E., Lee, G. B., Hong, B. U. \& Hwang, S. Y. Regeneration of activated carbons spent by waste water treatment using KOH chemical activation. Appl. Sci. Basel 9, 5132. https://doi.org/10.3390/app9235132 (2019).

13. Nunes, K. G. P., Sfreddo, L. W., Rosset, M. \& Feris, L. A. Efficiency evaluation of thermal, ultrasound and solvent techniques in activated carbon regeneration. Environ. Technol. https://doi.org/10.1080/0959330.2020.1746839 (2020).

14. Liu, P. et al. Kinetic study of microwave enhanced mercury desorption for the regeneration of spent activated carbon supported mercuric chloride catalysts. Chem. Eng. J. 408, 127355. https://doi.org/10.1016/j.cej.2020.127355 (2021).

15. Ferrandz-Gomez, B., Ruiz-Rosas, R., Beaumont, S., Cazorla-Amoros, D. \& Morallon, E. Electrochemical regeneration of spent activated carbon from drinking water treatment plant at different scale reactors. Chemosphere 264, 128399. https://doi.org/10. 1016/j.chemosphere.2020.128399 (2020).

16. Ganzoury, M. A., Chidiac, C., Kurtz, J. \& Delannoy, C. F. CNT-sorbents for heavy metals: Electrochemical regeneration and closedloop recycling. J. Hazard. Mater. 393, 122432. https://doi.org/10.1016/j.jhazmat.2020.122432 (2020).

17. Khan, M. M. et al. Hazardous wastewater treatment by low-cost sorbent with in situ regeneration using hybrid solar energyelecrochemical system. Water Environ. Res. https://doi.org/10.1002/wer.1537 (2021).

18. Chen, Q. W., Liu, F. \& Mo, J. H. Vertical macro-channel modification of a flexible adsorption board with in-situ thermal regeneration for indoor gas purification to increase effective adsorption capacity. Environ. Res. 192, 110218. https://doi.org/10.1016/j. envres.2020.110218 (2021). 
19. Lin, X. F., Fang, J., Chen, M. L., Huang, Z. \& Su, C. Y. Co and Fe-catalysts supported on sepiolite: Preparation conditions and their catalytic behaviors in high temperature gas flow treatment of dye. Environ. Sci. Pollut. Res. 23, 15294-15301. https://doi.org/10. 1007/s11356-016-6631-3 (2016).

20. Labiadh, L. \& Kamali, A. R. Textural, structural and morphological evolution of mesoporous $3 \mathrm{D}$ graphene saturated with methyl orange dye during thermal regeneration. Diam. Relat. Mater. 103, 107698. https://doi.org/10.1016/j.diamond.2020.107698 (2020).

21. Jawad, A. H. \& Abdulhameed, A. S. Mesoporous Iraqi kaolin clay as an efficient adsorbent for methylene blue dye: Adsorption kinetic, isotherm and mechanism study. Surf. Interfaces 18, 100422. https://doi.org/10.1016//j.surfin.2019.100422 (2020).

22. Gomez-Aviles, A. et al. Simultaneous adsorption of acetaminophen, diclofenac and tetracycline by organo-sepiolite: Experiments and statistical physics modelling. Chem. Eng. J. 404, 126601. https://doi.org/10.1016/j.cej.2020.126601 (2021).

23. Wu, J. Y., Wang, Y. H., Wu, Z. X., Gao, Y. \& Li, X. P. Adsorption properties and mechanism of sepiolite modified by anionic and cationic surfactants on oxytetracycline from aqueous solutions. Sci. Total Environ. 708, 134409. https://doi.org/10.1016/j.scitotenv. 2019.134409 (2020).

24. Zou, L. Y. et al. Pd/UIO-66/sepiolite: Toward highly efficient dual-supported Pd-based catalyst for dehydrogenation of formic acid at room temperature. J. Catal. 388, 66-76. https://doi.org/10.1016/j.jcat.2020.05.010 (2020).

25. Zhang, G., Xiong, Q., Xu, W. \& Guo, S. Synthesis of bicrystalline $\mathrm{TiO}_{2}$ supported sepiolite fibers and their photocatalytic activity for degradation of gaseous formaldehyde. Appl. Clay Sci. 102, 231-237. https://doi.org/10.1016/j.clay.2014.10.001 (2014).

26. Wang, F. et al. Novel fabrication of a sepiolite supported cobalt-based catalyst via a coprecipitation-reduction method. Appl. Clay Sci. 200, 105909. https://doi.org/10.1016/j.clay.2020.105909 (2021).

27. Ma, Y., Wu, X. \& Zhang, G. Core-shell Ag@Pt nanoparticles supported on sepiolite nanofibers for the catalytic reduction of nitrophenols in water: Enhanced catalytic performance and DFT study. Appl. Catal. B Environ. 205, 262-270. https://doi.org/10. 1016/j.apcatb.2016.12.025 (2017).

28. Wang, P. S., Qi, C. X., Hao, L. Y., Wen, P. C. \& Xu, X. Sepiolite/ $\mathrm{Cu}_{2} \mathrm{O} / \mathrm{Cu}$ photocatalyst: Preparation and high performance for degradation of organic dye. J. Mater. Sci. Technol. 35, 285-291. https://doi.org/10.1016/j.jmst.2018.03.023 (2019).

29. Tian, Y. Y. et al. Efficient fenton-like degradation of ofloxacin over bimetallic Fe-Cu@Sepiolite composite. Chemosphere 257, 127209. https://doi.org/10.1016/j.chemosphere.2020.127209 (2020).

30. Cerda-Moreno, C., Chica, A., Keller, S., Rautenderg, C. \& Bentrup, U. Ni-sepiolite and Ni-todorokite as efficient $\mathrm{CO}_{2}$ methanation catalysts: Mechanistic insight by operando DRIFTS. Appl. Catal. B-Environ. 264, 118546. https://doi.org/10.1016/j.apcatb.2019. 118546 (2020).

31. Bautista, F. M., Luna, D., Luque, J., Marinas, J. M. \& Sanchez-Royo, J. F. Gas-phase selective oxidation of chloro- and methoxysubstituted toluenes on $\mathrm{TiO}_{2}$-Sepiolite supported vanadium oxides. Appl. Catal. A-Gen. 352, 251-258. https://doi.org/10.1016/j. apcata.2008.10.015 (2009).

32. Zhou, F., Wang, H. Q., Zhou, S., Liu, Y. \& Yan, C. J. Fabrication of europium-nitrogen co-doped $\mathrm{TiO}_{2} /$ Sepiolite nanocomposites and its improved photocatalytic activity in real wastewater treatment. Appl. Clay Sci. 197, 105791. https://doi.org/10.1016/j.clay. 2020.105791 (2020)

33. Rezvani, M. A. \& Miri, O. F. Synthesis and characterization of PWMn/NiO/PAN nanosphere composite with superior catalytic activity for oxidative desulfurization of real fuel. Chem. Eng. J. 369, 775-783. https://doi.org/10.1016/j.cej.2019.03.135 (2019).

34. Menor, M., Sayas, S. \& Chica, A. Natural sepiolite promoted with $\mathrm{Ni}$ as new and efficient catalyst for the sustainable production of hydrogen by steam reforming of the biodiesel by-products glycerol. Fuel 193, 351-358. https://doi.org/10.1016/j.fuel.2016.12. 068 (2017).

35. Sayas, S. \& Chica, A. Furfural steam reforming over Ni-based catalysts: Influence of Ni incorporation method. Int. J. Hydrogen Energy 39, 5234-5241. https://doi.org/10.1016/j.ijhydene.2014.01.115 (2014).

36. Sayas, S. \& Chica, A. 21st world hydrogen energy conference. In WHEC, Proceeding, Zaragoza, pp. 1089-1090 (2016).

37. Balci, S. Thermal decomposition of sepiolite and variations in pore structure with and without acid pre-treatment. J. Chem. Technol. Biotechnol. 66, 72-78. https://doi.org/10.1002/(SICI)1097-4660(199605)66:1\%3c72::AID-JCTB442\%3e3.0.CO;2-T (1996).

38. Salvador, R., Casal, B., Yates, M., Martin-Luengo, M. A. \& Ruiz-Hitzky, E. Microwave decomposition of a chlorinated pesticide (Lindane) supported on modified sepiolites. Appl. Clay Sci. 22, 103-113. https://doi.org/10.1016/S0169-1317(02)00132-1 (2002).

39. Rodriguez, A., Ovejero, G., Mestanza, M. \& Garcia, J. Removal of dyes from wastewaters by adsorption on sepiolite and pansil. Ind. Eng. Chem. Res. 49, 3207-3216. https://doi.org/10.1021/ie9017435 (2010).

40. Kunii, D. \& Levenspiel, O. Fluidization Engineering 2nd edn. (Butterworth-Heinemann, 1991).

41. Levenspiel, O. The Chemical Reactor Omnibook (OSU Book Stores, 1989).

42. Konttinen, J. T., Zevenhoven, C. A. P., Yrjas, K. P. \& Hupa, M. M. Modeling of sulfided Zinc Titanate regeneration in a fluidizedbed reactor. 1: Determination of the solid conversion rate model parameters. Ind. Eng. Chem. Res. 36, 5432-5438. https://doi.org/ 10.1021/ie9700369 (1997).

43. Woods, M. C., Leese, K. E., Gangwal, S. K., Harrison, D. P. \& Jothimurugesan, K. Reaction kinetics and simulation models for novel high-temperature desulfurization sorbents: Final report, Contract Number DE-AC21-87MC24160 (Research Triangle Institute, 1989).

44. Woods, M. C., Gangwal, S. K., Jothimurugesan, K. \& Harrison, D. P. Reaction between $\mathrm{H}_{2} \mathrm{~S}$ and Zinc oxide-Titanium oxide sorbents. 1: Single-pellet kinetic studies. Ind. Eng. Chem. Res. 29, 1160-1167. https://doi.org/10.1021/ie00103a012 (1990).

\section{Acknowledgements}

This work was supported by the National Natural Science Foundation of China (grant number: 21166005), Natural Science Foundation of Guangxi (grant number: 2017GXNSFBA198216), the University Key Laboratory of Karst Ecology and Environmental Change of Guangxi Province (Guangxi Normal University) (grant number: YRHJ15Z020, YRHJ15Z025), Key Laboratory of Ecology of Rare and Endangered Species and Environmental Protection (Guangxi Normal University) (grant number: ERESEP2020Z19), Ministry of Education, China, the Young and Middle-aged Basci Capability Promotion from College of Guangxi (grant number: 2017KY077).

\section{Author contributions}

Conception (M.C.), experimental design (S.G., D.W.), experimental results analysis (Z.H., C.S.), manuscript composition (M.C., X.L.). All authors reviewed the manuscript.

\section{Competing interests}

The authors declare no competing interests.

\section{Additional information}

Supplementary Information The online version contains supplementary material available at https://doi.org/ 10.1038/s41598-022-06849-6. 
Correspondence and requests for materials should be addressed to M.C. or X.L.

Reprints and permissions information is available at www.nature.com/reprints.

Publisher's note Springer Nature remains neutral with regard to jurisdictional claims in published maps and institutional affiliations.

(c) (i) Open Access This article is licensed under a Creative Commons Attribution 4.0 International cc) License, which permits use, sharing, adaptation, distribution and reproduction in any medium or format, as long as you give appropriate credit to the original author(s) and the source, provide a link to the Creative Commons licence, and indicate if changes were made. The images or other third party material in this article are included in the article's Creative Commons licence, unless indicated otherwise in a credit line to the material. If material is not included in the article's Creative Commons licence and your intended use is not permitted by statutory regulation or exceeds the permitted use, you will need to obtain permission directly from the copyright holder. To view a copy of this licence, visit http://creativecommons.org/licenses/by/4.0/.

(C) The Author(s) 2022 